\title{
Sensitization to common aeroallergens in a population of young adults in a sub-Saharan Africa setting: a cross-sectional study
}

Bertrand Hugo Mbatchou Ngahane ${ }^{1,2^{*}}$, Diane Noah², Malea Nganda Motto², Yacouba Mapoure Njankouo ${ }^{1,2}$ and Louis Richard Njock ${ }^{3,4}$

\begin{abstract}
Background: Sensitization to aeroallergens increases the risk of developing asthma or allergic rhinitis. Data on sensitization to airborne allergens in the general population in sub-Saharan Africa are lacking. The aim of this study was to determine the prevalence and determinants of sensitization to common aeroallergens in a population of young adults.

Methods: A cross-sectional study was conducted among students of the Faculty of Medicine and Pharmaceutical Sciences of the University of Douala between 1st February and 30th April 2014. We consecutively recruited all the students present in class or in hospital during our visit. They filled an anonymous questionnaire and underwent skin prick tests with common aeroallergens. A logistic regression model of the SPSS.20 software was used to investigate factors associated with sensitization to common aeroallergens.

Results: Of the 600 students included in the study, 305 (50.8\%) were female. The mean age of participants was $22.6 \pm 2.7$ years. The prevalence of sensitization to aeroallergens was $42.8 \%$ (95 \% Cl 38.8-46.8). Dermatophagoides pteronyssimus (24.2 \%), Dermatophagoides farinae (22.8\%), Blomia tropicalis (23.3\%) and Blatella germanica (15.2 \%) were the most common allergens found. Allergic rhinitis, asthma symptoms and family atopy were independently associated to sensitization to common aeroallergens.
\end{abstract}

Conclusion: A significant proportion of young adults are sensitized to common aeroallergens. Dust mites and cockroach should be included in the panel of aeroallergens in Cameroon.

Keywords: Allergic sensitization, Skin prick test, Asthma, Allergic rhinitis, Africa

\section{Background}

The prevalence of allergic diseases is steadily increasing especially in middle- and low-income countries. The main manifestations of respiratory allergy which are asthma and allergic rhinitis are increasing rapidly these last 2 decades [1]. The number of asthma and allergic rhinitis patients worldwide are estimated at 334 and

\footnotetext{
*Correspondence: mbatchou.ngahane@yahoo.com

${ }^{1}$ Department of Internal Medicine, Douala General Hospital, PO Box 4856,

Douala, Cameroon

Full list of author information is available at the end of the article
}

400 million respectively [1, 2]. Asthma is associated with allergic rhinitis in $74-81 \%$ of cases [3] and is one of highest ranking specific diseases in terms of years lost to disability adjusted life years [4]. Atopy or allergic sensitization is defined as the production of immunoglobulin E (IgE) in response to allergens, especially inhaled allergens and food allergens [1]. It is an important step in the pathogenesis of IgE mediated allergic diseases and is therefore a major risk factor for the development of asthma and allergic rhinitis $[1,5,6]$. In order to design efficient preventive measures, it is useful to assess the prevalence and risk factors of allergic sensitization. 
In industrialized countries, there has been an increase over time of the sensitization to aeroallergens in the general population with a prevalence ranging from 25 to $50 \%[7,8]$. In Africa, most studies have been carried out in selected populations of asthma patients or allergic rhinitis patients. Nevertheless, Benzarti et al. in Tunisia found a $34 \%$ sensitization to common aeroallergens in a population of 500 subjects of an unselected population [9]. In another study carried out in Uganda, 14 and $20 \%$ of participants were respectively sensitized to Blomia tropicalis (BP) and Dermatophagoides pteronyssinus [10]. In Cameroon, we could not identify any studies on sensitization to aeroallergens in the general population. The objective of this study was to determine the prevalence and factors associated with sensitization to common allergens in a population of young adults.

\section{Methods}

\section{Design and study setting}

We conducted a cross-sectional study from February 1st to April 30th, 2014 among students of the Faculty of Medicine and Pharmaceutical Sciences of the University of Douala, who represented a sub-set of young adults in Douala, the most populated city of Cameroon. This seaside city is characterized by an equatorial climate with temperatures ranging from 21 to $31{ }^{\circ} \mathrm{C}$ with high rainfall from June to October. The relative humidity varies between 80 and $90 \%$ over the year.

\section{Participants}

The study population was made of students of the Faculty of Medicine and Pharmaceutical Sciences. We included students attending classes and those present in the hospitals for their internship during the study period. Pregnant students, those on antihistamines, those presenting with acute asthma and non consenting students were excluded. Based on an expected prevalence of sensitization to common aeroallergens of $34 \%$ [9] and considering an accepted error of $5 \%$ and a $95 \%$ confidence interval, a minimal sample size of 268 participants was required for this study.

\section{Data collection}

The recruitment of participants was completed at the university campus during break periods for students from grade 1 to grade 5 and in hospitals for grade 6 and grade 7 students. Using a self-administered questionnaire, the following data were collected: socio-demographic characteristics, home environment, smoking habits, personal and family history of atopy and asthma and allergic rhinitis symptoms. The questionnaires were returned to the investigator.
Skin prick tests were performed by two trained investigators according to the recommendations of the European Academy of Allergy and Clinical Immunology [11]. We used 8 standardized allergen extracts provided by ALK laboratories (Argonne in Varennes, France): the house dust mites Dermatophagoides pteronyssinus, Dermatophagoides farinae and Blomia tropicalis, the moulds Alternaria alternata and Aspergillus fumigates, cat dander, dog dander, and the cockroach Blatella germanica. Glycerosaline solution was used as the negative control and Histamine dihydrochloride $10 \mathrm{mg} / \mathrm{ml}$ as the positive control.

After cleaning of the volar aspect of the forearm with alcohol, a single drop of each test solution was applied on the skin. A skin-prick test was performed within the drop by pressing a lancet through the drop of allergen extract and holding it against the skin for at least $1 \mathrm{~s}$. The results of the tests were read $15 \mathrm{~min}$ following the application by measuring the largest diameter of the wheal of each allergen. The test was considered positive when the wheal diameter was greater or equal to $3 \mathrm{~mm}$. Allergic sensitization was defined as at least one positive reaction to the 8 aeroallergens used.

\section{Statistical analysis}

Data were entered and analyzed using IBM SPSS Statistics version 20.0. (Armonk, NY, USA: IBM Corp). Quantitative variables were summarized as means and standard deviations and qualitative data as frequencies and percentages. Univariate and multivariate logistic regression was used to determine the association between independent variables and sensitization to common aeroallergens. Variables with $\mathrm{p}<0.2$ in the univariate analysis were fitted into the final multiple logistic regression models. Variables with $p<0.05$ in the final model were taken as significant associated factors.

\section{Ethical clearance}

The study protocol was given ethical approval by the ethics committee of the Douala University and verbal consent was obtained from each participant before recruitment.

\section{Results}

Of the total of 680 students who received questionnaires, 608 returned the questionnaires to the investigator and underwent skin prick tests, giving a response rate of $89.4 \%$. Prick tests from eight subjects were not interpretable. The final study population consisted of 600 students of which 305 (58.8\%) were female. The mean age of participants was $22.7 \pm 2.8$ years (range 16-35). Symptoms suggestive of asthma and allergic rhinitis were found in $50(8 \%)$ and 301 (50.2\%) participants, respectively. The other characteristics of the study population are illustrated in Table 1. 
Table 1 Baseline characteristics of participants $(N=600)$

\begin{tabular}{|c|c|c|}
\hline Variables & Number & Percentage \\
\hline \multicolumn{3}{|l|}{ Gender } \\
\hline Male & 295 & 49.2 \\
\hline Female & 305 & 50.8 \\
\hline \multicolumn{3}{|l|}{ Age (years) } \\
\hline$<20$ & 79 & 13.2 \\
\hline $20-24$ & 359 & 59.8 \\
\hline $25-29$ & 158 & 26.3 \\
\hline$\geq 30$ & 4 & 0.7 \\
\hline \multicolumn{3}{|c|}{ Family atopy } \\
\hline Yes & 221 & 36.8 \\
\hline No & 379 & 63.2 \\
\hline \multicolumn{3}{|c|}{ Diagnosed asthma } \\
\hline Yes & 39 & 6.5 \\
\hline No & 561 & 93.5 \\
\hline \multicolumn{3}{|c|}{ Allergic rhinitis } \\
\hline Yes & 87 & 14.5 \\
\hline No & 513 & 85.5 \\
\hline \multicolumn{3}{|c|}{ Atopic dermatitis } \\
\hline Yes & 51 & 8.5 \\
\hline No & 549 & 91.5 \\
\hline \multicolumn{3}{|c|}{ Allergic conjunctivitis } \\
\hline Yes & 37 & 6.2 \\
\hline No & 563 & 93.8 \\
\hline \multicolumn{3}{|l|}{ Smoking } \\
\hline Yes & 11 & 1.8 \\
\hline No & 589 & 98.2 \\
\hline \multicolumn{3}{|c|}{ Alcohol consumption } \\
\hline Yes & 46 & 7.7 \\
\hline No & 554 & 92.3 \\
\hline \multicolumn{3}{|l|}{ Moulds } \\
\hline Yes & 352 & 58.7 \\
\hline No & 248 & 41.3 \\
\hline \multicolumn{3}{|c|}{ Carpet at home } \\
\hline Yes & 397 & 66.2 \\
\hline No & 203 & 33.8 \\
\hline \multicolumn{3}{|c|}{ Allergic rhinitis symptoms } \\
\hline Yes & 301 & 50.2 \\
\hline No & 299 & 49.8 \\
\hline \multicolumn{3}{|c|}{ Wheezing the last 12 months } \\
\hline Yes & 50 & 8.3 \\
\hline No & 550 & 91.7 \\
\hline
\end{tabular}

The skin prick tests were positive for at least one allergen in 257 subjects, giving a prevalence of allergic sensitization of $42.8 \%$ (95\% CI 38.8-46.8). D. farinae (24.2\%), B. tropicalis (23.3\%), D. pteronyssinus (22.8\%) and cockroach (15.2\%) were the most prevalent sensitizers (Fig. 1). The skin prick tests were positive for the 3 mites in $87(14.5 \%)$ participants while positive to both $D$. farinae and $D$. pteronyssinus in $107(17.8 \%)$ participants. The reactions were negative for $57.2 \%$ of participants. Sensitization to only one allergen was present in 79 (13.2\%) participants while the sensitization to 4 different allergens was observed in $4.5 \%$ of participants (Fig. 2). Of the 79 subjects with a monosensitization, cockroach was most represented (36, $7 \%$ ) followed by D. pteronyssinus (19\%) and B. tropicalis (13.9\%).

Univariate analysis indentified personal history of atopic dermatitis, family atopy, being exposed to cat at home, allergic rhinitis and wheezing during the 12 last months were significantly associated with sensitization to any aeroallergen (Table 2). The multivariate analysis revealed that, family atopy (OR 1.47, $95 \%$ CI 1-2.1), wheezing during the last 12 months (OR 3.12, $95 \% \mathrm{CI}$ $2.19-4,42)$ and allergic rhinitis symptoms $(2.43,95 \% \mathrm{CI}$ 1.27-4.66) were the factors independently associated to sensitization with common aeroallergens.

\section{Discussion}

This is the first study reporting on the pattern of allergic sensitization on a sample of young adults in subSaharan Africa. The prevalence of sensitization to common aeroallergens in this study was $41.8 \%$. Dust mites and cockroach were the most frequent allergens.

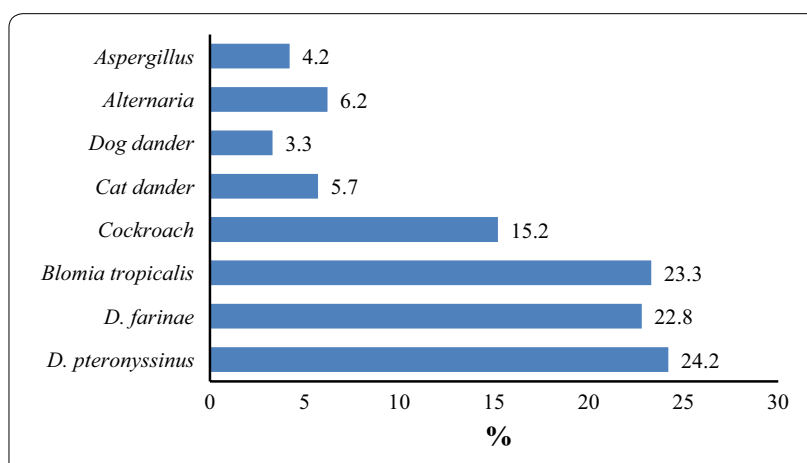

Fig. 1 Prevalence of sensitization to aeroallergens

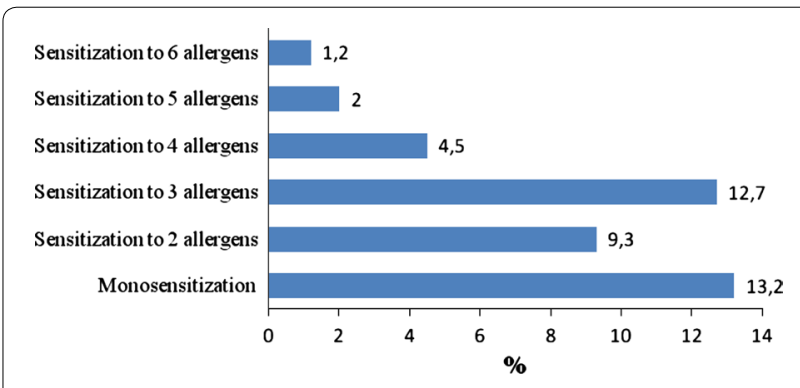

Fig. 2 Sensitization to one or more aeroallergens 
Table 2 Univariate and multivariate analysis of factors associated with sensitization to aeroallergens

\begin{tabular}{|c|c|c|c|c|}
\hline Variable & Positive skin prick test & P value & Adjusted odds ratio & Adjusted $P$ value \\
\hline Age (increase in) & & 0.15 & $1.06(0.99-1.13)$ & 0.06 \\
\hline BMI (increase in) & & 0.46 & - & - \\
\hline \multicolumn{5}{|l|}{ Sex } \\
\hline Male & $121(41 \%)$ & 0.77 & - & - \\
\hline Female & $135(44.6 \%)$ & & & \\
\hline \multicolumn{5}{|l|}{ Family atopy } \\
\hline Yes & $114(51.6 \%)$ & 0.001 & $1.47(1.02-2.10)$ & 0.03 \\
\hline No & $143(37.7 \%)$ & & & \\
\hline \multicolumn{5}{|l|}{ Atopic dermatitis } \\
\hline Yes & $29(56.9 \%)$ & 0.03 & $1.52(0.81-2.86)$ & 0.18 \\
\hline No & $228(41.5 \%)$ & & & \\
\hline \multicolumn{5}{|l|}{ Carpet at home } \\
\hline Yes & $194(44.7 \%)$ & 0.13 & $1.21(0.82-1.79)$ & 0.33 \\
\hline No & $63(38 \%)$ & & & \\
\hline \multicolumn{5}{|l|}{ Cat } \\
\hline Yes & 78 (49.7\%) & 0.04 & $1.41(0.96-2.09)$ & 0.07 \\
\hline No & 179 (40.4 \%) & & & \\
\hline \multicolumn{5}{|l|}{ Dog } \\
\hline Yes & $74(43 \%)$ & 0.95 & - & - \\
\hline No & $183(42.8 \%)$ & & & \\
\hline \multicolumn{5}{|l|}{ Moulds } \\
\hline Yes & $159(45.2 \%)$ & 0.16 & $0.98(0.68-1.41)$ & 0.94 \\
\hline No & $98(39.5 \%)$ & & & \\
\hline \multicolumn{5}{|c|}{ Allergic rhinitis symptoms } \\
\hline Yes & $174(57.8 \%)$ & $<0.001$ & $3.12(2.19-4.42)$ & $<0.001$ \\
\hline No & $83(27.8 \%)$ & & & \\
\hline \multicolumn{5}{|c|}{ Wheezing during the last 12 months } \\
\hline Yes & $34(68 \%)$ & $<0.001$ & $2.43(1.27-4.66)$ & 0.007 \\
\hline No & $223(40.5 \%)$ & & & \\
\hline
\end{tabular}

Monosensitization was observed in $13.2 \%$ of the sample and cockroach was the most implicated allergen. We also found an independent association between positive skin prick tests and family atopy, allergic rhinitis symptoms and asthma symptoms.

Many studies have been conducted worldwide showing a high prevalence of positive skin prick tests to common aeroallergens in the general population. In Europe, the Global Allergy and Asthma European Network survey showed that this prevalence varied from 31.4 to $52.9 \%$ [12] while in the United States, a similar trend was observed in 2 national surveys, with almost half of the population aged 6 years and over having at least one positive skin prick test to common allergens [7, 13]. Another study in Vietnam found that one-third of the population was sensitized to common allergens [14]. In Africa, we found one study in Tunisia, showing a prevalence of $34 \%$. In sub-Saharan Africa, studies in general population are scarce. In Cameroon, a recent study showed that $32 \%$ of a population of individuals with no allergic symptoms had one or more positive skin prick test to common aeroallergens [15].

In our study population, mites were the most common allergens. This is consistent with previous reports from different regions of the world [5, 7, 9, 12, 15]. Similar results were also found in asthma patients in sub-Saharan Africa [16, 17]. Cockroach was the fourth most frequent allergen in our study after the 3 mites. This finding corroborates previous studies in sub-Saharan Africa [15, 17]. The high prevalence of sensitization to both mites and cockroaches in this study is explained by the high relative humidity and hot climate observed in the city of Douala. In western countries, there is a geographical variation of the prevalence of sensitization to aeroallergens, with cockroach sensitization generally less frequent [7, 12, 18]. However, some studies conducted in Eastern Europe showed a high prevalence of cockroach sensitization [19, 20]. 
Sensitization to the other allergens such as moulds, as well as cat and dog dander had relative low prevalence in this study. Conversely, in European and North American countries, sensitization to cat and dog dander have a more important place among common aeroallergens [7, 18 . In these countries, the two pets are present more frequently in homes than they are in subSaharan Africa.

The independent association between sensitization to common aeroallergens and allergic rhinitis or asthma in the current study confirms previous findings [1]. Positive skin prick tests are considered as a hallmark of atopy. Indeed, it is well known that this genetic predisposition to develop IgE-mediated sensitivity to common aeroallergens is the strongest identifiable predisposing factor to the development of allergic rhinitis and asthma [21]. In sub-Saharan Africa, many studies had demonstrated the association between sensitization to mites and asthma. These mites are the main contributor to sensitization to common aeroallergens [22-24]. Having a family history of atopy was associated to sensitization to common aeroallergens. This finding which is in line with the results of Pallasaho et al. in Finland [25] can be explained by the genetic factors that influence the expression of atopy. In fact, allergy and organ-based phenotypes have strong heritability, but the exact genes involved in the expression of different disease phenotypes are only just being revealed and studies are still ongoing [26].

We did not find any association between sensitization to commons allergens and age. This is probably due to the fact that our participants were all young adults, with a mean age of 22.7 years. We could not compare them with a younger or older population. Usually, the rate of allergic sensitization decreases with increasing age [25, 27].

This study has several limitations: first the measurement of serum specific IgE to help confirm sensitization was not performed in this study. Secondly, we did not perform skin prick tests to pollens. This was because the commercial extracts available are adapted to the vegetation of western countries which are not necessarily present in sub-Saharan Africa. Another limitation of this study is the fact that our results cannot be generalizable to the whole Cameroon population because we included a selected population of university students in this study.

\section{Conclusion}

This study revealed that a significant proportion of young adults in Cameroon are sensitized to common aeroallergens with dust mites identified as the most prevalent allergens. In order to recommend proper allergen avoidance and to prescribe allergen specific immunotherapy, skin prick tests containing mites and cockroach allergens should be considered in patients presenting with symptoms of asthma and allergic rhinitis.

\section{Authors' contributions}

BHMN conceived and designed the study, analyzed the data and drafted the manuscript. ND drafted the study protocol and collected the data. NMM, YMN and NLR revised the manuscript. All authors read and approved the final manuscript.

\section{Author details}

${ }^{1}$ Department of Internal Medicine, Douala General Hospital, PO Box 4856, Douala, Cameroon. ${ }^{2}$ Faculty of Medicine and Pharmaceutical Sciences, University of Douala, Douala, Cameroon. ${ }^{3}$ Department of Ear Nose and Throat, Douala General Hospital, Douala, Cameroon. ${ }^{4}$ Faculty of Medicine and Biomedical Sciences, University of Yaounde 1, Yaounde, Cameroon.

\section{Acknowledgements}

The authors thank all of the medical students who participated in this study. They also thank the Pan African Thoracic Society MECOR course staff for their suggestions during the preparation of the manuscript.

\section{Competing interests}

The authors declare that they have no competing interests.

\section{Funding}

This research received no specific grant from any funding agency in the public, commercial or not-for-profit sectors.

Received: 22 August 2015 Accepted: 17 December 2015

Published online: 04 January 2016

\section{References}

1. Pawankar R, Canonica GW, Holgate ST, Lockey RF, Blaiss MS. The World Allergy Organization (WAO) White Book on Allergy: Update 2013. Wisconsin: Milwaukee; 2013.

2. Global Asthma Network. The Global Asthma Report 2014. http://www. globalasthmareport.org. Accessed 24 May 2015.

3. Leynaert B, Neukirch C, Kony S, Guenegou A, Bousquet J, Aubier M, Neukirch F. Association between asthma and rhinitis according to atopic sensitization in a population-based study. J Allergy Clin Immunol. 2004;113(1):86-93.

4. Masoli M, Fabian D, Holt S, Beasley R. The Global Burden of Asthma Report. http://www.ginasthma.org. Accessed 24 May 2015.

5. Leung R, Ho P, Lam CW, Lai CK. Sensitization to inhaled allergens as a risk factor for asthma and allergic diseases in Chinese population. J Allergy Clin Immunol. 1997;99:594-9.

6. Peat JK, Britton WJ, Salome CM, Woolcock AJ. Bronchial hyperresponsiveness in two populations of Australian schoolchildren. III. Effect of exposure to environmental allergens. Clinical Allergy. 1987;17(4):291-300.

7. Salo PM, Arbes SJ Jr, Jaramillo R, Calatroni A, Weir CH, Sever ML, Hoppin JA, Rose KM, Liu AH, Gergen PJ, et al. Prevalence of allergic sensitization in the United States: results from the National Health and Nutrition Examination Survey (NHANES) 2005-2006. J Allergy Clin Immunol. 2014;134(2):350-9.

8. Dottorini ML, Bruni B, Peccini F, Bottini P, Pini L, Donato F, Casucci G, Tantucci C. Skin prick-test reactivity to aeroallergens and allergic symptoms in an urban population of central Italy: a longitudinal study. Clin Exp Allergy. 2007;37(2):188-96.

9. Benzarti M, Mezghani S, Jarray M, Garrouche A, Khirouni S, Klabi N. Skin test reactivity to seven aeroallergens in a Sousse area population sample. La Tunisie Médicale. 2002;80:450-4.

10. Mpairwe H, Muhangi L, Ndibazza J, Tumusiime J, Muwanga M, Rodrigues LC, Elliott AM. Skin prick test reactivity to common allergens among women in Entebbe, Uganda. Trans R Soc Trop Med Hyg. 2008;102(4):367-73.

11. Heinzerling L, Mari A, Bergmann K-C, Bresciani M, Burbach G, Darsow U, Durham S, Fokkens W, Gjomarkaj M, Haahtela T, et al. The skin prick testEuropean standards. Clin Trans Allergy. 2013;3:3.

12. Newson RB, van Ree R, Forsberg B, Janson C, Lötvall J, Dahlén S-E, Toskala EM, Baelum J, Brożek GM, Kasper L, et al. Geographical variation in the 
prevalence of sensitization to common aeroallergens in adults: the GA(2) LEN survey. Allergy. 2014;69:643-51.

13. Arbes SJ, Gergen PJ, Elliott L, Zeldin DC. Prevalences of positive skin test responses to 10 common allergens in the US population: results from the Third National Health and Nutrition Examination Survey. J Allergy Clin Immunol. 2005;116:377-83.

14. Lâm HT, Ekerljung L, Bjerg A, Văn T, Tng N, Lundbäck B, Rönmark E. Sensitization to airborne allergens among adults and its impact on allergic symptoms: a population survey in northern Vietnam. Clin Trans Allergy. 2014;4:6.

15. Pefura-Yone EW, Mbele-Onana $C L$, Balkissou AD, Kenmegne-Noums EC, Boulleys-Nana JR, Kolontchang-Yomi BL, Theubo-Kamgang BJ, Ndjeutcheu-Moualeu PI, Ebouki ER, Kengne AP. Perennial aeroallergens sensitisation and risk of asthma in African children and adolescents: a case-control study. J Asthma 2014:1-5.

16. Mbatchou Ngahane BH, Agodokpessi G, Mapoure NY, Akazong AC, Fonyam V, Barla E, Njock LR. Prévalence de la sensibilisation aux pneumallergènes chez des patients asthmatiques. Etude préliminaire à Douala, Cameroun. Revue de Médecine et de Pharmacie 2013; 3(2):354-58.

17. Agodokpessi G, Ade G, Dovoedo N, Ade S, Wachinou AP, Fayomi B, Gninafon M. Sensitisation profile to airborne allergens of patients followed for asthma in Cotonou, Benin. A cross-sectional study using prick-tests. Rev Mal Respir. 2014.

18. Bousquet PJ, Chinn S, Janson C, Kogevinas M, Burney P, Jarvis D, European Community Respiratory Health Survey I. Geographical variation in the prevalence of positive skin tests to environmental aeroallergens in the European Community Respiratory Health Survey I. Allergy. 2007;62(3):301-9.

19. Raukas-Kivioja A, Raukas E-S, Meren M, Loit H-M, Rönmark E, Lundbäck B. Allergic sensitization to common airborne allergens among adults in Estonia. Int Arch Allergy Immunol. 2007;142:247-54.
20. Eriksson NE, Holmén A, Möller C, Wihl JA. Sensitization according to skin prick testing in atopic patients with asthma or rhinitis at 24 allergy clinics in Northern Europe and Asia. Allergol Int. 1998;47:187-96.

21. Weinmayr G, Weiland SK, Bjorksten B, Brunekreef B, Buchele G, Cookson WO, Garcia-Marcos L, Gotua M, Gratziou C, van Hage M, et al. Atopic sensitization and the international variation of asthma symptom prevalence in children. Am J Respir Crit Care Med. 2007;176(6):565-74.

22. Addo-yobo EO, Custovic A, Taggart SC, Craven M, Bonnie B, Woodcock A. Risk factors for asthma in urban Ghana. J Allergy Clin Immunol. 2001;108(3):363-8.

23. El Fekih L, Mjid M, Souissi Z, Ben Hmida A, El Gueddari Y, Douagui H, Ouedraogo M, Dan Aouta M, Beji M. Sensitization to three house dust mites (Dermatophagoïdes pteronyssinus, Dermatophagoïdes farinae, Blomia tropicalis) in asthmatic and rhinitic patients living in the Maghreb and sub-Saharan Africa. Revue Française d'Allergologie. 2014;54:107-12.

24. Pefura-Yone EW, Kengne AP, Kuaban C. Sensitisation to mites in a group of patients with asthma in Yaounde, Cameroon: a cross-sectional study. BMJ Open. 2014;4(1):e004062.

25. Pallasaho P, Rönmark E, Haahtela T, Sovijärvi ARA, Lundbäck B. Degree and clinical relevance of sensitization to common allergens among adults: a population study in Helsinki, Finland. Clin Exp Allergy J Br Soc Allergy Clin Immunol. 2006;36:503-9.

26. Ober C, Yao T-C. The genetics of asthma and allergic disease: a $21 \mathrm{st}$ century perspective: genetics of asthma and allergy. Immunol Rev. 2011;242:10-30.

27. Cline MG, Burrows B. Distribution of allergy in a population sample residing in Tucson, Arizona. Thorax. 1989;44(5):425-31.

\section{Submit your next manuscript to BioMed Central and we will help you at every step:}

- We accept pre-submission inquiries

- Our selector tool helps you to find the most relevant journal

- We provide round the clock customer support

- Convenient online submission

- Thorough peer review

- Inclusion in PubMed and all major indexing services

- Maximum visibility for your research

Submit your manuscript at www.biomedcentral.com/submit

() Biomed Central 